\title{
Признаки минералого-геохимической зональности металлоносных образований Цзямусы-Ханкайской графитоносной провинции
}

\author{
Молчанов В.П. ${ }^{1}$, Андросов Д.В. ${ }^{1}$, Молчанова Н.Н. ${ }^{2}$ \\ ${ }^{1}$ Дальневосточный геологический институт ДВО РАН, Владивосток, vpmol@mail.ru \\ 2ОOО «Гидрометаллург», Владивосток,631135@mail.ru
}

Аннотация. В пределах единой зоны региональной графитизации, вытянутой в субмеридиональном направлении на многие десятки километров сопредельных территорий Приморья (Россия) и провинции Хэйлунцзян (КНР), с участием авторов, выявлены многочисленные проявления благороднометальной минерализации, отнесенные к одной Цзямусы-Ханкайской провинции. На ее северном фланге расположены объекты Дальнереченской группы (наиболее крупное - Филинское), в центре - месторождения Лесозаводской группы (Тургеневское, Тамгинское), на юге - графитоворудный гигант Люмао. Сравнительным анализом установлены черты сходства их геологии, минералогии и геохимии. Наблюдаемые различия рудных образований отражают существование, как минимум, двух контрастных геохимических зон - нижнерудной (Филинское месторождение) и верхнерудный (Тургеневское и Люмао).

Ключевые слова: зональность, высокоуглеродистые породы, юг Дальнего Востока РФ, Северо-Восток КНР, минералогия, геохимия.

\section{Signs of the mineralogical and geochemical zonality of the metal-bearing formations of the Jiamusi-Hankai graphite-bearing province}

\author{
Molchanov V.P. ${ }^{1}$, Androsov D.V. ${ }^{1}$, Molchanova N.N. ${ }^{2}$ \\ ${ }^{1}$ Far East Geological Institute, Far Eastern Branch of the RAS, Vladivostok, vpmol@mail.ru \\ ${ }^{2}$ Limited Liability Company «Hydrometallurg»,Vladivostok, Russia,631135@mail.ru
}

\begin{abstract}
Numerous manifestations of noble metal mineralization attributed to the same Jiamusi-Khanka province have been defined within a single zone of regional graphitization extended in a submeridional direction for many tens of kilometers of adjacent territories of Primorye (Russia) and Heilongiiang (China), with the participation of the authors of the proposed work. On the northern flank there are facilities of the Dalnerechenskoye group (Filinskoe is the largest), in the center there are deposits of the Lesozavodskoye group (Turgenevskoye and Tamginskoye), and in the south there is a graphite-ore giant, Liumao. Comparative analysis has established similar features of their geology, mineralogy and geochemistry. The observed differences in the ore formations reflect the existence of at least two contrasting geochemical zones - the lower ore (Filinskoe deposit) and the upper ore (Turgenev and Liumao).

Key words: zonality, high carbon rocks, the south of the Far East of the Russian Federation, the Northeast of China, mineralogy, geochemistry.

\section{Введение}

Многие наукоемкие технологии, являющиеся показателями уровня развития промышленного производства передовых стран, немыслимы без использования графита. Уникальные свойства этого минерала вместе с последними открытиями в области ядерной энергетики, электроники и нанотехнологий полностью поменяли наше представление о возможностях его использования. В странах Европейского союза и Китае графит внесен в список критических минералов. Основные месторождения высококачественного кристаллического графита располагаются в Китае, Индии, Бразилии, Чехии, Канаде и Мексике. При этом, основным производителем и экспортером графитового сырья является Китай. Немногочисленные российские предприятия, специализирующиеся на добыче графита, лишь в малой степени обеспечивают потребности нашей страны в графитовой продукции. Основная часть кристаллического графита ввозится из-за рубежа. Одним из направлений обеспечения национальной безопасности России является создание новых центров добычи и переработки графитовых руд высокого качества. Выполненные исследования позволят наметить основ-
\end{abstract}


ные направления промышленного освоения российских месторождений графита юга Дальнего Востока, их комплексного использования и глубокой переработки высокоуглеродистого минерального сырья.

\section{Результаты исследований и их обсуждение}

Высокоуглеродистые породы занимают обширные территории в пределах Дальнего Востока РФ и Северо-Востока КНР. Только в Приморском крае они образуют широкую зону, вытянутую в субмеридиональном направлении на многие десятки километров вдоль границы Ханкайского и Цзямусы террейнов от г. Дальнереченска на севере через г. Лесозаводск до г. Цзиси (провинция Хэйлунцзян, КНР). В пределах зоны установлен ранний этап регионального метаморфизма низкоградиентного широкозонального типа в условиях амфиболитовой и эпидот-амфиболитовой фаций, возраст которого составил 730 млн. лет. Поздний этап метаморфизма от гранулитовой до зеленосланцевой фаций связан с коллизионными событиями на рубеже кембрия и ордовика. Одним из важнейших результатов геологических исследований последних десятилетий в пределах этой зоны является открытие (Ханчук и др., 2004) проявлений благороднометально-редкоземельной минерализации. В ее северной, российской, части (Дальнереченская площадь) выявлено пять месторождений (наиболее крупное из них - Филинское), в центре (Лесозаводская площадь) расположено свыше тридцати объектов (в том числе известные месторождения графита Тамгинское и Тургеневское), а в южном, китайском, сегменте (Машаньская площадь) размещено около сорока месторождений, в том числе и графитоворудный гигант Люмао, на долю которого приходится более половины мировой добычи кристаллического графита. Учитывая широкое площадное проявление металлоносных графитизированных пород при их значительной мощности по вертикали (до 3000 м), можно полагать, что они, помимо графита, аккумулируют значительные ресурсы благородных металлов (БМ) и редкоземельных элементов (РЗЭ). Было предложено (Ханчук и др., 2017) объединить упомянутые графитоносные площади в одну Цзямусы-Ханкайскую провинцию.

\section{Дальнереченская металлоносная площадь}

Наиболее крупное месторождение площади, Филинское, открытое с участием авторов (Khanchuk et al., 2018), приурочено к породам нижней (ружинской) свиты рудовмещающего разреза отложений иманской серии. Специфика его рудных образований состоит в тесной связи с процессами регионального метаморфизма, проявившегося в условиях от гранулитовой до амфиболитовой фации. Комплекс рудовмещающих пород представлен переслаиванием мраморов, кальцифиров, биотит-кварц-полевошпатовых сланцев и согласных инъекций биотитовых и лейкократовых гранито-гнейсов. Породы сильно дислоцированы, смяты в антиклинальную складку субмеридионального простирания. Восточное крыло складки прорвано штоком лейкократовых гранитов. Отмечается присутствие секущих слоистую толщу маломощных жил, сложенных кварцем и полевым шпатом. По контактам с гранитами и гранито-гнейсами мрамора скарнированы. В мраморах и сланцах графит в ассоциации с сульфидами и флюоритом развит в виде тонкочешуйчатой равномерно рассеянной вкрапленности, в скарнах и гранито-гнейсах образует крупные мономинеральные гнезда, жилы и прожилки.

Рудная минерализация, ассоциирующая с графитом, характеризуется сложным полиминеральным составом. Самородное золото чаще всего представлено частицами неправильных очертаний. Диапазон гранулометрической шкалы этих обособлений невелик (10-20 мкм). По химическому составу их можно отнести к высокопробным разновидностям. Лишь в отдельных золотинах фиксируется примесь $\mathrm{Cu}$ до 1-2 \%. Самородное серебро обнаружено в виде проволоковидных выделений размером до 10-15 мкм. В некоторых из них присутствует $\mathrm{Cu}(0.9 \%)$. В ассоциации с минералами БМ и графитом отмечаются сульфиды (пирит, пирротин, пентландит, халькопирит, сфалерит, Со - содержащий арсенопирит, галенит, висмутин, тетрадимит), а также барит, рутил, монацит, ксенотим, уранинит. Наряду с ними довольно часто встречаются зерна $\mathrm{Yb}$ - содержащего (до 1 \%) флюорита, образующего с кварцем графические срастания. 
В изученных графитизированных породах установлен широкий спектр элементов. Отличительными чертами рудовмещающих пород являются повышенные концентрации $\mathrm{Al}_{2} \mathrm{O}_{3}$ и щелочей при преобладании $\mathrm{Na}_{2} \mathrm{O}$ над $\mathrm{K}_{2} \mathrm{O}$, а также $\mathrm{Y}, \mathrm{Cr}, \mathrm{Zn}, \mathrm{Ni}, \mathrm{Rb}, \mathrm{Zr}, \mathrm{Ba}, \mathrm{Pb}$, Th.

По характеру распределения РЗЭ графитоносные породы разделяются на две группы: одну с низким суммарным содержанием РЗЭ и положительной европиевой аномалией и другую с более высоким содержанием РЗЭ и отрицательной европиевой аномалией. В первую из них попадают граниты, во вторую - все остальные разновидности пород изученной площади. Различия в амплитуде европиевой аномалии могут отражать разную глубину магматического очага. Тренды распределения РЗЭ в гранитах описываются кривыми, отражающими резкое обогащение легкими и средними лантаноидами относительно тяжелых (отношение $\mathrm{La} / \mathrm{Yb}$ достигает $55, \mathrm{La} / \mathrm{Sm}-16.5$ ). Суммарное содержание РЗЭ составляет 59 г/т.

Углеродистым породам второй группы свойственно значительное преобладание легких РЗЭ над тяжелыми. Максимальные концентрации РЗЭ зафиксированы у углеродистых сланцев ( 2 РЗЭ до 740 г/T, La/Yb 110-120). Им близки хондрит - нормализованные тренды распределения РЗЭ в скарнах, графитовых жилах и гранито-гнейсах. Они также обогащены легкими РЗЭ относительно тяжелых (La/Yb 11-24), но располагаются в области более низких концентраций Р3Э. Кварцевые жилы представлены компактной группой трендов, отражающих максимальное снижение всех РЗЭ ( $\sum$ РЗЭ до 5-11 г/т). Им свойственна незначительная европиевая аномалия, а также уменьшение величины отношении $\mathrm{La} / \mathrm{Sm}$ и $\mathrm{Gd} / \mathrm{Yb}$. Это выражается в слабом проявлении дифференциации как среди легких, так и тяжелых лантаноидов.

Все отмеченные разновидности пород графитизированы, концентрация элементарного углерода в отдельных случаях достигает 20 мас. \%. Выполненные анализы указывают на наличие тенденции снижения степени графитизации пород в направлении от скарнов к кварцевым жилам. Более того, сопоставление полученных данных показало, что в образцах с повышенными содержаниями графита и золота (0.1-0.2 г/т) постоянно присутствуют значительные количества лантаноидов. Тесная ассоциация редкоземельных и благородных металлов с графитом свидетельствуют в пользу их генетического родства, являясь признаком происхождения из единого рудогенерирующего источника. Этот факт имеет важное прикладное значение, поскольку позволяет контролировать не только качество исходного благороднометально-редкоземельно-графитового материала, но и корректировать направление будущих технологических исследований.

\section{Лесозаводская металлоносная площадь}

Критическая ситуация с графитовым сырьем в современной России вызвала интерес к выявленным в прошлом высокоуглеродистым породам юга Дальнего Востока, в частности, Тургеневскому и Тамгинскому месторождениям. Разведочными работами сороковых годов прошлого столетия (Солоненко, 1951) они были отнесены к числу крупнейших в СССР источников кристаллического графита. Им посвящены многочисленные публикации сотрудников ДВГИ ДВО РАН (Ханчук и др., 2004, 2010, 2018 и т.Д), установивших присутствие значительных ресурсов благородных металлов. В этих работах дана детальная характеристика по минералогии и петрографии пород и руд, приводятся сведения о изотопно-геохимических особенностях рудных образований, рассматриваются проблемы их генезиса. Согласно цитированным источникам, Тургеневское месторождение, которому посвящены основные исследования авторов, расположено в Ружинском метаморфическом комплексе, в ядре которого вскрыт эрозией комплекс пород верхней тургеневской свиты уссурийской серии, измененных в условиях амфиболитовой фации (участок «Западный»). Комплекс представлен переслаиванием гранат-биотит-полевошпатовых, биотит-кварц-полевошпатовых кристаллосланцев и плагиогнейсов с мраморами и согласными инъекциями биотитовых и лейкократовых очковых гранито-гнейсов. Мрамора на контакте с гранито-гнейсами скарнированы. Отмечается присутствие маломощных (до 1 м) согласных со сланцеватостью даек лампрофиров габбро-диоритового состава щелочного (калиевого) уклона. На крыльях Ружинского купола обнажены позднепротерозойские черные апотерригенные аспидные и филлитовидные графит-серицит-кварцевые сланцы ми- 
трофановской свиты лесозаводской серии, с высоким (до 12 мас. \%) содержанием углерода («Восточный» участок). Степень их метаморфизма отвечает зеленосланцевой фации. Представленные на месторождении литологические разности пород подвержены процессам наложенной графитизации в виде дисперсных фаз, мономинеральных жил и линзовидных включений. В кристаллосланцах графит ориентирован согласно слоистости, в то время как в гранито-гнейсах и лампрофирах преобладают секущие прожилки и линзовидные скопления. Содержание углерода варьирует от долей процента до 39 мас. \%.

Рудная минерализация, ассоциирующая с графитом, характеризуется довольно сложным полиминеральным составом и многообразием форм распределения благородных и редкоземельных металлов. Отмечено присутствие сульфидов (киновари, пирита, сфалерита, галенита, халькопирита), металлических твердых растворов и интерметаллических соединений $(\mathrm{Au}, \mathrm{Hg}),(\mathrm{Au}, \mathrm{Cu})$, ( $\mathrm{Au}, \mathrm{Ag}, \mathrm{Cu}, \mathrm{Hg}),(\mathrm{Au}, \mathrm{Pd}, \mathrm{Ag}, \mathrm{St}),(\mathrm{Au}, \mathrm{Ag}, \mathrm{U}, \mathrm{F}),(\mathrm{Pt}, \mathrm{Fe}, \mathrm{Cu}),(\mathrm{Cu}, \mathrm{Sn}),(\mathrm{Cu}, \mathrm{Zn})$, монацита, ксенотима и т.д.

В графитовых рудах самородное золото нередко образует микронные и субмикронные выделения в виде сфероидальных обособлений (до 2 мкм), состав которых обнаруживает значительные колебания от 1000 до 980 \%. Спорадически в золоте отмечаются примеси $\mathrm{Ag}, \mathrm{Cu}, \mathrm{Hg}$ (до 1-2 \%). Самородное золото в скарнах отличает комковидно-губчатая форма, более крупные (до 1 мм) размеры и повышенное (до 10 мас. \%) содержание Ag. На поверхности его зерен образуется углеродистая нанопленка, в составе которой, помимо С (56-60 мас. \%), присутствуют О (19-33 \%) и примесь $\mathrm{Si}, \mathrm{Al}, \mathrm{Ca}, \mathrm{Fe}$ и $\mathrm{Cl}$ (до 1 мас.\%). Наиболее низкопробная разновидность золота (мас.\%): $\mathrm{Au}$ - 60-65, $\mathrm{Ag}-33-34, \mathrm{Cu}-1-2$ встречается в прожилково-вкрапленных зонах. В нем обнаружена примесь, мас. \%: U $-3.42, \mathrm{~W}-1.26$ и постоянно присутствует фтор со значительными колебаниями содержания от единиц до 34.66 мас. \%.

Самородная платина представлена дискретными зернами неправильной формы, равномерно рассеянными в графитовой и силикатной матрице пород (участок «Западный»). В графит-серициткварцевых сланцах участка «Восточного» обнаружены единичные тонкопризматические кристаллы изоферроплатины (мас. \%): $\mathrm{Pt}-90.36, \mathrm{Fe}-9.64$.

В графитизированных породах установлен широкий спектр элементов от петрогенных вплоть до $\mathrm{Au}, \mathrm{Pt}, \mathrm{Hg}, \mathrm{Cu}, \mathrm{Sn} \mathrm{La}, \mathrm{Ce}$ и редких земель. Наиболее высокие содержания Р3Э характерны для лампрофиров, в которых их суммарные содержания достигают 1 мас. \%. Кроме того, результаты проведения комплекса анализов свидетельствуют о том, что в лампрофирах концентрируется максимум БМ, (г/т): $\mathrm{Pt}-62, \mathrm{Au}-49, \mathrm{Pd}-1.1$ и $\mathrm{Rh}-5, \mathrm{Ag}-8.2$. Содержание золота в графитизированных гранито-гнейсах, графит-серицит-кварцевых сланцах и скарнах варьирует в широких пределах, достигая (г/т): 17.41, 13.01 и 8.50, соответственно.

Анализ подвижности РЗЭ в различных процессах показал, что они мобильны при гидротермальных и метасоматических процессах, менее мобильны при низко- и умеренно температурном метаморфизме и условно инертны при высокотемпературном метаморфизме. Имеющиеся данные указывают, что по характеру распределения РЗЭ графитоносные породы, как и в случае с Филинским месторождением, разделяются на две группы. Первая из них представлена гранитами, во вторую входят все остальные разновидности пород изученной площади, включая низкотемпературные гидротермальные образования. Близки у них и конфигурации графиков распределения микроэлементов. Граниты характеризуются той же положительной европиевой аномалией и резким преобладанием легких лантаноидов над тяжелыми (отношение $\mathrm{La} / \mathrm{Yb}$ достигает 118). Суммарное содержание РЗЭ составляет 93 г/т.

Породам второй группы, так же как филинским, свойственны отрицательная европиевая аномалия и значительная преобладание легких лантаноидов над тяжелыми. Наиболее тяжелые концентрации РЗЭ зафиксированы у скарнов, лампрофиров и амфиболитов ( $\sum$ Р3Э до 255 г/T, La/Yb 12-18). В области более низких концентраций РЗЭ расположены кристаллосланцы, графит-серицит кварцевые сланцы. Величина отношения $\mathrm{La} / \mathrm{Yb}$ при этом варьирует от 6 до 11. Минимальные концентрации РЗЭ (до 18-21 г/т) имеют кварцевые и кварц-карбонатные жилы, располагаясь в нижней части 
графика субгоризонтальной компактной группой. Выполненные анализы содержаний элементного углерода показывают, что дифференциация РЗЭ сопровождается снижением степени графитизации в направлении от скарнов к жилам. При этом, как и в рудных образованиях Филинского месторождения, отмечается наличие корреляции между содержаниями золота, графита и РЗЭ. Тесные связи редкоземельных и благородных металлов с графитом в месторождениях Дальнереченской и Лесозаводской площадей еще раз свидетельствует в пользу их генетического родства, являясь признаком происхождения из единого рудогенерирующего источника.

\section{Машаньская металлоносная площадь}

Графитоворудный гигант Люмао в структурном плане приурочен к террейну Цзямусы. Специфика его рудных образований определяются тесными связями с высокоуглеродистыми породами серии Машань, претерпевшими метаморфизм от гранулитовой до амфиболитовой фации. В геологическом строении объекта принимают участие гранат-силлиманитовые, силлиманитгранат-кордиеритовые, графитовые и кварцевые сланцы, гранито-гнейсы, переслаивающиеся с мраморами (Jiang Jisheng, 1992, 1993). Для рудовмещающих пород характерны щелочной (калиевый) уклон, высокие концентрации $\mathrm{Al}_{2} \mathrm{O}_{3}, \mathrm{TiO}_{2}$ и низкие $-\mathrm{Na}_{2} \mathrm{O}, \mathrm{CaO}$. Имеет место отрицательная корреляция между содержаниями $\mathrm{SiO}_{2}$ и $\mathrm{Al}_{2} \mathrm{O}_{3}$ и $\mathrm{TiO}_{2}$. Последние характеризуются положительными корреляционными связями. Графитоносные образования характеризуются повышенными содержаниями элементарного углерода (до 40 мас. \%), а также U, V, Ag). В тоже время, как показывают наши исследования, в высокоуглеродистых породах по данным атомно-абсорбционной спектрометрии содержания золота достигают уровня 0.12-0.15 г/т, а платины - 0.01-0.02 г/т. Близкие значения были получены с применением методов нейтронно-активационного анализа.

Диаграммы распределения редкоземельных элементов показывают, что графитоносные породы серии Машань обогащены легкими лантаноидами, для них характерны отрицательная европиевая аномалия и низкие концентрации тяжелых редкоземельных элементов. Сопоставление их с графиками распределения редкоземельных элементов в породах месторождений Лесозаводской и Дальнереченской площадей показывает синформность кривых всех типов пород, что однозначно указывает на их единую природу происхождения.

Рудная минерализация, ассоциирующая с графитом, характеризуется сложным полиминеральным составом и разнообразием форм распределения благородных металлов в виде самородных элементов, твердых растворов. Самородное золото чаще всего представлено частицами неправильных форм. Диапазон гранулометрической шкалы этих обособлений невелик (1-10 мкм). По химическому составу они подразделяются на четыре группы: беспримесную, серебристую, медистую и серебросодержащую медистую. Первая из них объединяет золотины с очень высокой частотой (до 999 единиц). Вторая группа - частицы с содержанием Ag от 5.13 до 51.92 мас. \%. В третью группу входит медьсодержащие (Сu обычно от 0.92-1.37 мас. \%, максимальное значение до 12.75 мас. \%) без примеси серебра. Четвертая группа включает обособления трехкомпонентных твердых растворов Au-Ag-Cu. Концентрация серебра в них не превышает 8.3 мас. \%, а уровень содержания меди варьирует в пределах от 14.3 до 29.6 мас. \%.

В зафиксированных зернах твердого раствора на основе платины содержание железа и меди колеблется в диапазоне 8.7-10.9 и 1.4-1.5 (мас. \%), соответственно. Размеры этих комковидных либо удлиненно - неправильных частиц обычно не превышают 2-3 мкм. Самородное серебро обнаружено в виде округлых выделений размером от 3 до 15 мкм. В некоторых из них присутствует медь (0.4-0.5 мас. \%). В ассоциации с минералами БМ часто фиксируются изометричные зерна (до 6 мкм) самородного никеля. В число других попутных минералов входят сульфиды (пирит, галенит), а также барит, рутил, монацит, ксенотим, хромферид, уранинит. Наряду с ними довольно редко встречаются тонкие минеральные фазы, содержащие вольфрам, ртуть, олово, медь, цинк, стронций и др.

Таким образом, полученная информация по самородным золоту, платине, никелю и другим рудным минералам графитоносных пород месторождений Люмао хорошо согласуются с приведенными выше данными по минералогии и геохимии месторождений Дальнереченской и Лесозавод- 
ской групп, что свидетельствует в пользу общности минералого-геохимической картины формирования рудоносных объектов в пределах зоны региональной графитизации. Полученные ранее данные по изотопии углерода графита российских и китайских месторождений (Ханчук и др., 2017; Khanchuk et al., 2018) позволяют полагать, что в формировании сингенетичной им рудной минерализации провинции участвовали в по меньшей мере два изотопно-контрастных источника: флюиды мантийного происхождения и осадочные породы с органическими соединениями. Широкие вариации изменений изотопного состава углерода $\left(\delta^{13} \mathrm{C}\right.$ от 3.1 до $26.6 \%$ ) отражает различный вклад биогенного углерода. В любом случае, главными поставщиками углерода при формировании благороднометально-редкоземельно-графитоносных руд были глубинные флюидные потоки.

Сравнительный анализ месторождений Дальнереченской, Лесозаводской и Машаньской групп обнаруживает удивительную близость их геохимических и минералогических характеристик. Наблюдающиеся различия в минералого-геохимической специализации рудных образований отражают существование, как минимум, двух контрастных геохимических зон - нижнерудной (Филинское месторождение) и верхнерудной (Тургеневское и Люмао). При этом если золото занимает устойчивые позиции на каждом из двух уровней, то платина является геохимическим индикатором лишь месторождений верхней зоны.

\section{Заключение}

Приведенные материалы по геологии, минералогии и геохимии металлоносных образований высокоуглеродистых пород сопредельных территорий юга Дальнего Востока РФ и Северо-Востока КНР позволяют достаточно обосновано отнести площади рудолокализации месторождений Лесозаводской, Дальнереченской и Машаньской групп к одной графитоносной Цзямусы-Ханкайской провинции. Принадлежность графитоносных объектов к этой провинции в дальнейшем может служить основой для решения важных генетических вопросов, моделирования процессов рудообразования в высокоуглеродистых породах, совершенствования приемов переработки графитового материала. Так, промышленное освоение приморских месторождений графита сдерживается отсутствием технологий извлечения полезных компонентов. В этих условиях представляется необходимо учесть многолетний опыт технологического передела руд китайского аналога - месторождения Люмао, обеспечивающего до 70 \% потребности КНР в кристаллическом графите.

Работа выполнена при поддержке гранта РФФИ № 17-05-00910.

\section{Литература}

1. Солоненко В.П. Геология месторождений графита Восточной Сибири и Дальнего Востока. М.Изд-во: Геол. литер. 1951. 383 с.

2. Ханчук А.И. и др. Первые данные о золото-платиноидном оруденении в углеродистых породах Ханкайского массива, Приморье // Докл. РАН. 2004. Т. 379. № 4. С. 524-529.

3. Ханчук А.И. и др. Благородные металлы в графитосодержащих породах месторождения Люмао (Китай) // Докл. РАН. 2017.T. 473. № 1.С. 80-82.

4. Jiang Jisheng. Regional Metamorphism and Evolution of Mashan Khondalite Series // Acta petrologica et mineralogica. 1992. V. 11 (2). P. 97-110.

5. Jiang Jisheng. Geochemistry of Mashan-group khondalite series // Geochimica. 1993. V. 12 (4). P. 363-372.

6. Khanchuk A.I., Molchanov V. and Androsov D. First data about the manifestations of the noble-metallicallyrare-earth mineralization in the graphytonic rocks of the northern market of the Khankai terrain // Doklady Earth Sciences. 2018. V. 482(2). P. 1362-1364. 